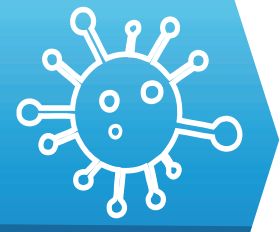

INFECTIOUS DISEASESS

1) Pathology Department, Adesh Institute of Medical Sciences and Research, Bathinda, India

2) Pathology Department, Bhaskar Medical College \& General Hospital, Hyderabad, India

3) Pathology Department, Focus Imaging \& Research Centre PVT. LTD. New Delhi, India

4) Pathology Department, KVG Medical College \& Hospital, Karnataka, India

DOI: $10.15386 /$ cjmed-1030

Manuscript received: 22.03 .2018 Received in revised form: 10.06 .2018 Accepted: 19.06.2018

Address for correspondence: ruchi2001@gmail.com

\section{Kimura disease: case report and brief review of literature}

Harshi Dhingra ${ }^{1}$, Ruchi Nagpal ${ }^{2}$, Asif Baliyan ${ }^{3}$, Sathyavathi R Alva ${ }^{4}$

\begin{abstract}
Kimura disease is a rare chronic inflammatory disorder of unknown cause, primarily seen in young Asian males. The disease is characterized by painless subcutaneous swelling, blood and tissue eosinophilia and raised IgE levels. Early diagnosis of Kimura's disease may spare the patient from unnecessary invasive diagnostic procedure. We describe a case of Kimura disease in a 14-year old male presenting with left submandibular swelling and also provide a brief review of the literature.
\end{abstract}

Keywords: Kimura disease, eosinophilia, IgE

\section{Introduction}

Kimura disease (KD) is a rare chronic inflammatory disorder of unknown etiology [1]. It usually presents as subcutaneous mass in the head and neck region and is frequently associated with regional lymphadenopathy or salivary gland involvement $[1,2] . \mathrm{KD}$ is rare in India, only 200 cases have been reported worldwide since its histopathological diagnosis [3]. It is generally seen in young adults, with most patients being in the age group of 20 and 40 years; men are affected more commonly than women, with a $3: 1$ ratio $[4,5]$. The disease is endemic in Asians, but occurs sporadically in other racial groups [5]. The commonly involved sites are periauricular, groin, orbit, and eyelids. Peripheral blood eosinophilia and elevated serum immunoglobulin E (IgE) levels are constant features of Kimura's disease [6]. Coexisting renal disease is common, with an incidence ranging from $10 \%$ to $60 \%$ [5]. The diagnosis of KD is often difficult, and the biopsy or excision of the involved mass for a pathological study is necessary. Here we report a rare case of a 14-year old male with left submandibular swelling.

\section{Case Report}

A 14-year old male patient presented to the surgical Outpatient Department (OPD) with the complaint of submandibular swelling for the past 2 years which was insidious in onset and gradually progressive. He had no history of any constitutional symptoms. On examination, a $5 \times 2 \mathrm{~cm}$ lobulated, non tender, firm cervical mass was seen in the left submandibular region, which was non adherent to the mandible. The skin overlying the swelling was not involved. The rest of the examination was unremarkable. Hematological examination revealed $\mathrm{Hb} 12.5 \mathrm{gm} / \mathrm{dl}$, TLC 9,500 cells/ cumm (Neutrophils 32\%, Lymphocytes $42 \%$, Eosinophils 24\%, Monocytes $2 \%$ ) and adequate platelets. Fine needle aspiration (FNA) of the lymph node was performed. Smears were cellular and composed of polymorphous population of lymphoid cells, histiocytes and endothelial cell clusters. Background showed abundant eosinophils, lymphohistiocytes, mixed inflammatory cell infiltrate, fibrous stroma and hemorrhage (Figure 1). Features were suggestive of chronic non specific lymphadenitis with eosinophilia. Excision biopsy was advised and performed. The specimen received consisted of two lymph nodes, the largest measuring $2.5 \times 2 \times 0.5$ $\mathrm{cm}$. Outer surface was irregular and the cut surface was homogenous grey white (Figure 2). Histopathological sections studied from lymph node showed partial effacement of architecture. The cortex revealed aggregates of lymphoid follicles of varying sizes with hyperplastic germinal centers (Figure 3) infiltrated by many eosinophils and histiocytes (Figure 4). Deposition of proteinaceous material and eosinophilic abscesses were also seen (Figure 5). Medulla showed aggregates of histiocytes, eosinophils and dense endothelial proliferation (Figure 6). Histological features were suggestive of Kimura's disease. 


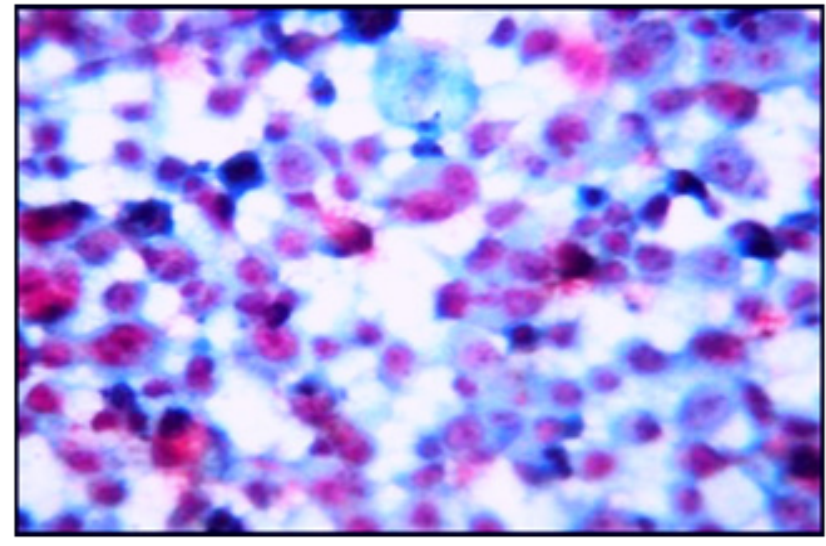

Figure 1. Polymorphous population of lymphoid cells with eosinophils (MGG stain, 40X).

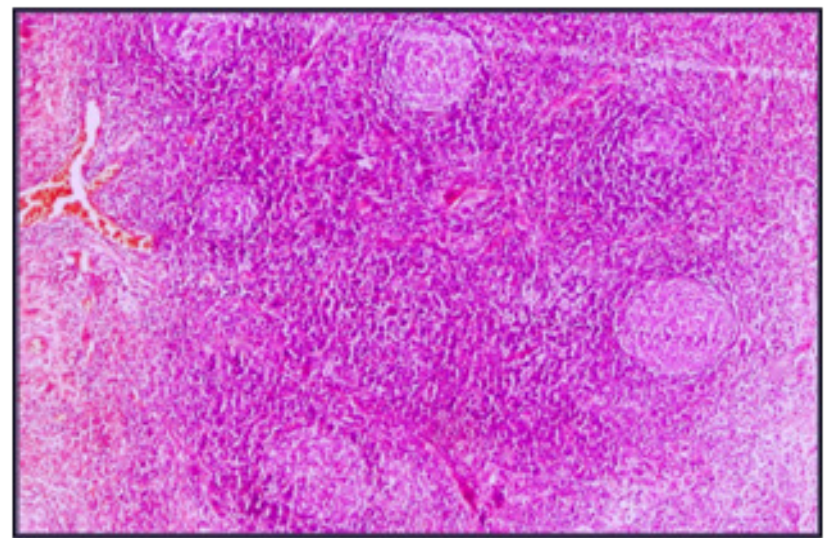

Figure 3. Hyperplastic follicles with germinal centers (H\&E stain, 10X).

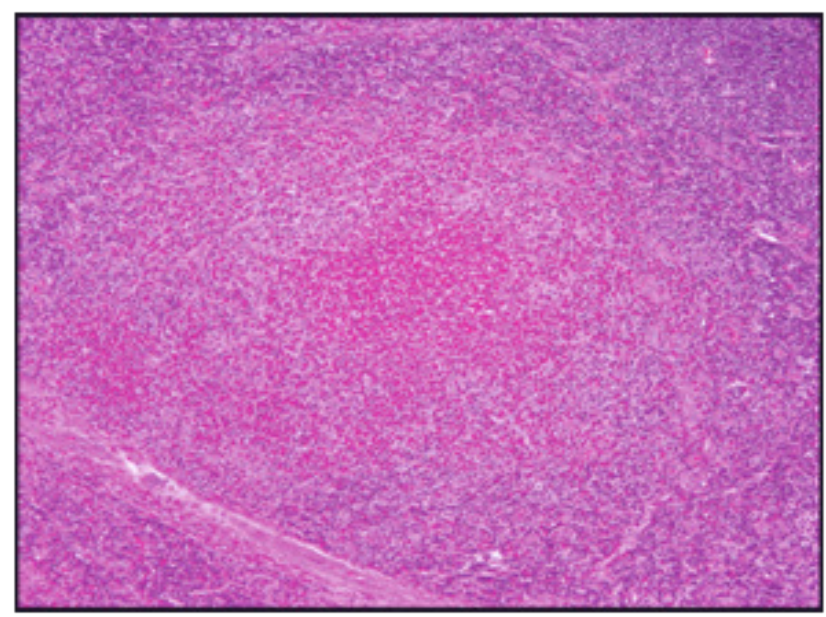

Figure 5. Prominent eosinophilic infiltrate with microabscess formation (H\&E stain, 10X).

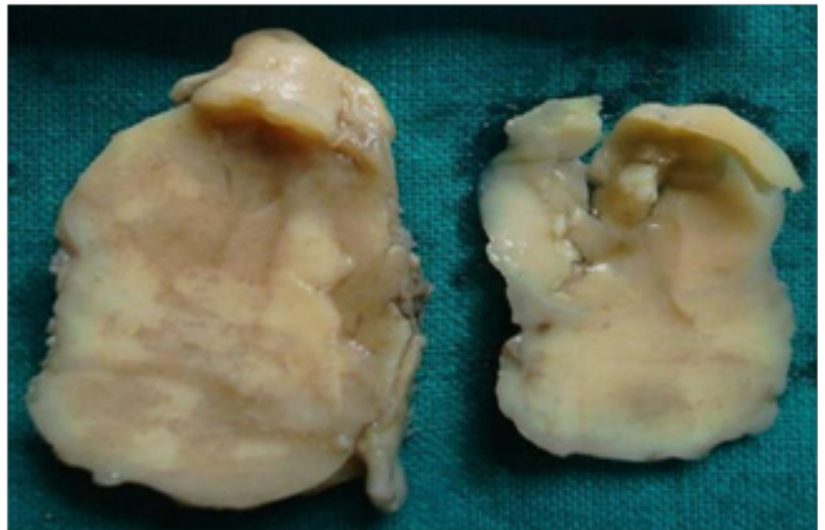

Figure 2. Gross image of the homogenous grey white cut surface of the lymph node.

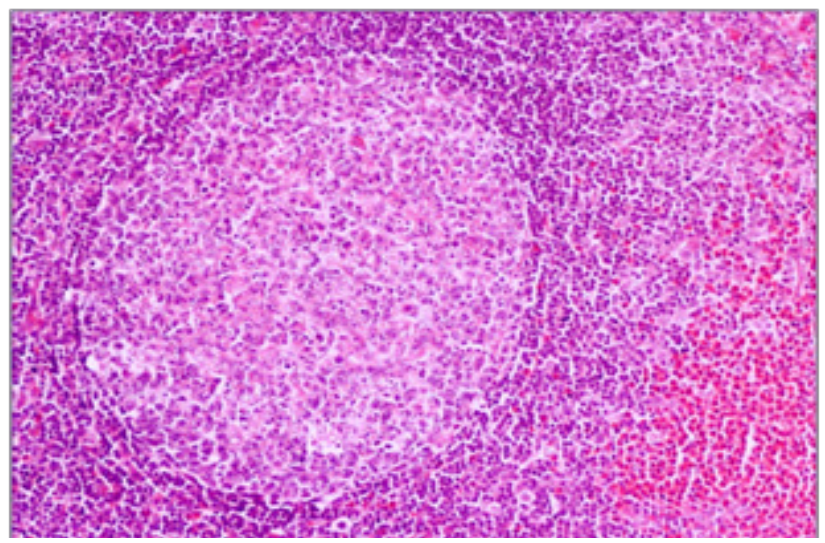

Figure 4. Germinal center infiltrated by eosinophils and histiocytes (H\&E, 40X).

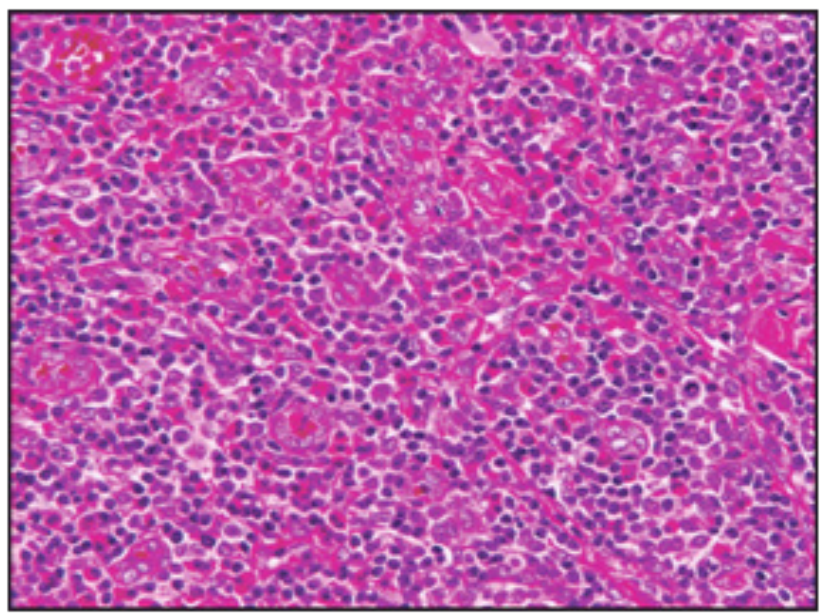

Figure 6. Endothelial cell proliferation with lumen containing RBCs in the medulla (H\&E stain, 40X). 


\section{Discussion}

Kimura Disease (KD) is a rare chronic inflammatory disorder, which was first described in 1937 by Kim and Szeto in the Chinese literature as "eosinophilic hyperplastic lymphogranuloma" and has been known most often as Kimura's disease since its description by Kimura et al. in the Japanese literature in 1948. This disease is endemic in middle-aged Asian males and rarely seen sporadically in non-Asian population [5]. However, Chen et al. concluded in their study that though rare, if clinical suspicion arises, $\mathrm{KD}$ should be included in any race in the differential diagnosis of any lymph node demonstrating an eosinophilic infiltrate and prominent follicular hyperplasia [7]. The disease can be seen at any age, the 2nd and 3rd decades of life being the most common. Men are more commonly affected than women, with a ratio of 3:1 [4,5]. It presents predominantly as subcutaneous nodules in the head and neck, often unilateral, and frequently associated with regional lymphadenopathy with or without the involvement of salivary glands. Sometimes bilateral involvement is also seen. Orbit, eyelid, palate, and pharynx have also been reported to be involved, in addition to the axilla, groin, and arm [6,7]. The clinical course is generally benign and self-limited. Most patients have a prolonged course with gradual increase in the swelling. Occasional spontaneous resolution is seen.

The exact cause and pathogenesis of Kimura's disease are still unclear, although it might be a self-limited allergic or autoimmune response triggered by an unknown persistent antigenic stimulus. Studies have also shown that the proliferation of CD4+ T cells, specifically the CD4 T-helper2 (Th2) cells and resultant overproduction of their cytokines, such as granulocyte macrophage colonystimulating factor, tumor necrosis factor- $\alpha$, IL-4, IL-5, eotaxin, and RANTES trigger the production of lymphoid follicle and high IgE [8]. Clonal T-cell population attributes to the disease development and recurrence [9]. The immune reaction that is believed to be the root of Kimura's disease also predisposes the patient to allergic conditions like asthma, chronic urticaria, pruritus and rhinitis [8]. Moreover, up to $60 \%$ of these patients exhibit renal involvement manifesting as extra membranous glomerulonephritis and nephrotic syndrome [10]. Although there is no specific diagnostic feature of Kimura disease, FNA is helpful in preoperative diagnosis of Kimura's disease. Smears show significant numbers of eosinophils in a background of lymphoid cells with occasional fragments of collagenous tissue and Warthin-Finkeldey polykaryocytes [11]. In our case of FNA smears revealed polymorphous population of lymphoid cells, histiocytes and endothelial cell clusters in the background of abundant eosinophils, lymphohistiocytes, fibrous stroma and hemorrhage.

Hui et al. classified the histological features of Kimura's disease as constant, frequent and rare [7,12]. The constant features include preserved nodal architecture, florid germinal center hyperplasia, eosinophilic infiltration and postcapillary venule proliferation. Frequent features comprise sclerosis, polykaryocytes, vascularization of the germinal centers, proteinaceous deposits in the germinal centers, necrosis of the germinal centers, eosinophilic abscesses and reticular IgE deposition within germinal centers. The solitary rare feature is the progressive transformation of the germinal centers. Nodal architecture is largely preserved in most cases, however, capsular fibrosis with subcapsular sinusoid obliteration and perinodal soft tissue involvement is frequently present [7]. In our case, there was partial effacement of the nodal architecture. Aggregates of lymphoid follicles of varying sizes with hyperplastic germinal centers infiltrated by dense eosinophils and histiocytes were seen. Deposition of proteinaceous material and eosinophilic abscesses were also noted. Medulla showed aggregates of histiocytes, eosinophils and dense endothelial proliferation.

The diagnosis of $\mathrm{KD}$ is not easy and differential diagnosis includes angiolymphoid hyperplasia with eosinophilia (ALHE), Hodgkin's disease, Kaposi sarcoma, eosinophilicgranuloma, epithelioidhemangioma, Castleman's disease, tuberculosis, dermatopathic lymphadenopathy, lymphadenopathy of drug reactions, parasitic lymphadenitis, eosinophilic granuloma, epithelioid hemangioma and many more [7]. The closest differential is ALHE. Clinically, both conditions present as soft tissue swellings arising in the head and neck region with prolonged indolent clinical course. Microscopically, both show eosinophilic infiltrates and vascular proliferations. But there are few characteristic and distinctive clinicopathologic features that differentiate the two entities. KD occurs predominantly in Asians, with a male predilection. Patients usually have peripheral eosinophilia and elevated serum IgE levels. The solitary lesions are mostly in the subcutaneous tissues, frequently associated with regional lymphadenopathy and salivary gland involvement. By contrast, ALHE occurs in all racial groups with a slight female predominance. Patients present with small, superficial dermal papulonodules, frequently erythematous, accompanied by bleeding, pruritis, and tumor growth. Regional lymphadenopathy, serum eosinophilia, and elevated IgE levels are rare [13]. Histologically, KD has three components: cellular (inflammatory infiltrate including increased eosinophils and follicular hyperplasia), fibrocollagenous and vascular (arborizing vascular proliferation of the postcapillary venule, endothelial cells are usually flat and lack cytologic atypia or vacuolization). In contrast to $\mathrm{KD}$, vascular proliferation is most significant in ALHE, forming aggregates or lobules comprising of plump endothelial cells with epithelioid or histiocytoid changes demonstrating cytologic atypia and vacuolization [7,14]. Summary of the differences between the KD and ALHE is discussed in table I. The list of other differentials with their clinical, cytological, and histological features are mentioned in the table II $[1,7,9,15]$. 
Table I. Clinical and pathological differences between Kimura disease and ALHE.

\begin{tabular}{|c|c|c|}
\hline & KIMURA DISEASE & ALHE \\
\hline Prevalence & Predominantly in Asians, with a male predilection & $\begin{array}{l}\text { All racial groups with a slight female } \\
\text { predominance }\end{array}$ \\
\hline Eosinophilia and raised serum IgE & Usually seen & Rare \\
\hline Gross lesions & $\begin{array}{l}\text { Solitary lesions are mostly in the deep subcutaneous } \\
\text { tissues, frequently associated with regional } \\
\text { lymphadenopathy and salivary gland involvement. }\end{array}$ & $\begin{array}{l}\text { Small, superficial dermal papulonodules, } \\
\text { frequently erythematous, accompanied by } \\
\text { bleeding and pruritus. } \\
\text { Regional lymphadenopathy is rare. }\end{array}$ \\
\hline Histological features & $\begin{array}{l}\text { Three components: cellular (inflammatory infiltrate } \\
\text { including increased eosinophils and follicular } \\
\text { hyperplasia), fibrocollagenous and vascular (arborizing } \\
\text { vascular proliferation of the postcapillary venule, } \\
\text { endothelial cells are usually flat and lack cytologic atypia } \\
\text { or vacuolization) }\end{array}$ & $\begin{array}{l}\text { Vascular proliferation is most significant, } \\
\text { forming aggregates or lobules comprising of } \\
\text { plump endothelial cells with epithelioid or } \\
\text { histiocytoid changes demonstrating cytologic } \\
\text { atypia and vacuolization }\end{array}$ \\
\hline
\end{tabular}

Table II. Cytological and histological features of other differential diagnosis.

\begin{tabular}{|c|c|c|}
\hline ENTITY & CYTOLOGICAL FINDINGS & HISTOLOGICAL FINDINGS \\
\hline $\begin{array}{l}\text { Angiolymphoid hyperplasia } \\
\text { with eosinophilia (ALHE) }\end{array}$ & $\begin{array}{l}\text { Spindle-shaped, polygonal cells with vesicular } \\
\text { nuclei and deeply eosinophilic cytoplasm } \\
\text { containing well-defined vacuoles and plenty of } \\
\text { immunoblasts }\end{array}$ & $\begin{array}{l}\text { Vascular proliferation is most significant forming aggregates } \\
\text { or lobules comprised of plump endothelial cells with } \\
\text { epithelioid or histiocytoid changes, frequently } \\
\text { demonstrating cytologic atypia and vacuolization }\end{array}$ \\
\hline Hodgkin lymphoma & $\begin{array}{l}\text { Eosinophils, plasma cells and atypical cells- } \\
\text { presence of Reed-Sternberg cells }\end{array}$ & $\begin{array}{l}\text { Presence of Reed-Sternberg cells determines a positive } \\
\text { diagnosis. Eosinophils, plasma cells, and sclerosis seen; but } \\
\text { lacks the hyperplastic germinal centers and deposits of IgE }\end{array}$ \\
\hline Castleman disease & $\begin{array}{l}\text { Prominent vascularity with hyalinized capillaries } \\
\text { and eosinophilic granular material }\end{array}$ & $\begin{array}{l}\text { Vascular hyperplasia but lacks eosinophilia and has atrophic } \\
\text { rather than hyperplastic germinal centers }\end{array}$ \\
\hline $\begin{array}{l}\text { Dermatopathic } \\
\text { lymphadenopathy }\end{array}$ & Pigment containing histiocytes & $\begin{array}{l}\text { Follicular hyperplasia, sclerosis, and deposits of } \\
\text { hemosiderin, melanin and lipids }\end{array}$ \\
\hline Drug reactions & Eosinophils & Comprise eosinophils but drug history is important. \\
\hline Parasitic infection & Granuloma and/or eosinophilia & $\begin{array}{l}\text { Granuloma and/or eosinophilia. Detection of parasite } \\
\text { remnants may lead to the diagnosis }\end{array}$ \\
\hline
\end{tabular}

Imaging studies might be diagnostic and can help in staging the extent and progression of the disease as well as the lymph node involvement. The diagnosis in our case was only through the histopathological examination of the excised tissue. Thus, the cytological features of reactive hyperplasia with the presence of eosinophils should at least clinch the diagnosis of Kimura's disease at cytology in appropriate clinical settings.

Therapies for KD include surgical excision, steroids and radiation. Surgical excision may be considered first especially for the localized lesion, even if recurrence is possible [8]. Systemically administered steroids show good effects on disease progression; however, withdrawal of steroids can often result in relapse. Radiation has been utilized for steroid resistant lesions.

\section{Conclusion}

The relevance of this case is due to the rarity of the disease which mimics neoplastic conditions. KD should be considered as a differential diagnosis in patients presenting with head \& neck mass and lymphadenopathy and investigated accordingly. Knowledge of Kimura's disease will put the physicians in a better position to diagnose and treat the disease.

\section{References}

1. Ioachim H, Ratech H. Kimura lymphadenopathy. In: Ioachim H, Ratech H, eds. Ioachim's Lymph Node Pathology. 3rd ed. Philadelphia: Lippincott-Raven, 2002, pp 209-11.

2. Abhange RS, Jadhav RP, Jain NK. Kimura disease: A rare case report. Ann Pathol Lab Med 2018;5:53-55.

3. Rajesh A, Prasanth T, Naga Sirisha VC, Azmi M. Kimura's disease: A case presentation of postauricular swelling. Niger J Clin Pract. 2016;19:827-830.

4. Tseng CF, Lin HC, Huang SC, Su YC. Kimura's disease presenting as bilateral parotid masses. Eur Arch of Otorhinolaryngol. 2005;262:8-10.

5. Fouda MA, Gheith O, Refaie A, El-Saeed M, Bakr A, Wafa E, et al. Kimura disease: a case report and review of the literature with a new management protocol. Int J Nephrol. 2011;2010:673908.

6. Shetty AK, Beaty MW, McGuirt WF Jr, Woods CR, Givner LB. Kimura's disease: a diagnostic challenge. Pediatrics. 2002;110:e39.

7. Chen H, Thompson LD, Aguilera NS, Abbondanzo SL. Kimura disease: a clinicopathologic study of 21 cases. Am J Surg Pathol. 2004;28:505-513. 
8. Meningaud JP, Pitak-Arnnop P, Fouret P, Bertrand JC. Kimura's disease of the parotid region: report of 2 cases and review of the literature. J Oral Maxillofac Surg. 2007;65:134-140.

9. Chong WS, Thomas A, Goh CL. Kimura's disease and angiolymphoid hyperplasia with eosinophilia: two disease entities in the same patient: case report and review of the literature. Int $\mathbf{J}$ Dermatol. 2006;45:139-145.

10. Abhay H, Swapna S, Darshan T, Vishal J, Gautam P. Kimura's Disease: A Rare Cause of Local Lymphadenopathy. Int J Sci Stud. 2014;2:122-125.

11. Deshpande AH, Nayak S, Munshi MM, Bobhate SK.
Kimura's disease. Diagnosis by aspiration cytology. Acta Cytol. 2002;46:357-363.

12. Hui PK, Chan JK, Ng CS, Kung IT, Gwi E. Lymphadenopathy of Kimura's disease. Am J Surg Pathol. 1989;13:177-186.

13. Vimal S, Panicker NK, Soraisham P, Chandanwale SS. Kimura disease. Med J DY Patil Univ. 2013;6:208-211.

14. Swarnkar M, Agrawal A. Kimura's disease. Formos J Surg. 2018;51:26-28.

15. Kini U, Shariff S. Cytodiagnosis of Kimura's disease. Indian J Pathol Microbiol. 1998;41:473-477. 